\title{
Psychiatry on the Internet: survey of an OCD mailing list
}

\author{
Dan J. Stein
}

\begin{abstract}
Professionals and consumers have joined psychiatric support groups on the Internet. This paper reports on a survey of members of an obsesstve-compulstve disorder (OCD) malling list (OCD-L). Members, who were primarly patients with OCD, but included family members and professionals, were generally posttive about the benefits of the list, finding It a useful source of information about treatment, and a helpful source of support. It is concluded that a usetul component of the management of OCD may include joining OCD-L. or a similar Internet support group, as benefits seem to outweigh poseible problems. Further study of other Internet psychiatic support groups, which may differ signilicantly trom OCD-L, seems warranted.
\end{abstract}

Rapid changes in telecommunications have already led to important changes in scientific research and medical practice, and will undoubtedly lead to further developments in the future (Preston et al, 1992; Baer et al, 1995; Noam, 1995). Of particular interest to psychiatry is the recent proliferation of psychiatric support groups on the Internet. Professionals and consumers alike have joined forums devoted to such subjects as mood disorders, clinical psychopharmacology. and psychoanalytic research (Huang \& Alessi, 1995).

Such forums would appear to offer several advantages, including rapid and easy communication, ready access to information and data, and collaboration and support. On the other hand, information and data on the Internet may be difficult to find or blatantly incorrect, and social relations on the Internet have been described as sometimes superficial and transient (Turkle, 1995). Little research has, however, so far documented the benefits and problems of psychiatry support groups on the Internet.

In this study members of an Internet mailing list devoted to obsessive-compulsive disorder (OCD) were surveyed. Members of the list were asked in detail about their experience of belonging to the list.

\section{The study}

A mailing list known as the obsessive-compulsive disorder list (OCD-L) has been in operation for over a year. It was started by a family member of a patient with OCD, and now typically has over 150 members at any one time. OCD-L has been advertised in the newsletter of the ObsessiveCompulsive Foundation (OCF), a consumer organisation for patients with OCD and their families, and can also be found by using an Internet search program to list sites relevant to OCD.

Access to mailing lists such as OCD-L is obtained via the Internet, using a personal computer and modem. Many academic institutions provide an Internet service for staff and students, and private Internet service providers also offer fairly inexpensive Internet access to the public. Subscription to OCD-L can be initiated by simply sending an electronic mail (e-mail) message "subscribe $x x x$ " (where $x x x$ is the subscriber's e-mail address) to the OCD-L computer server (listserv@vm.marist.edu).

Subscribers to mailing lists such as OCD-L communicate by sending e-mail messages to a particular computer server, which then automatically distributes this message to all subscribers. Each message is given a header (e.g. "Serotonin in OCD") by the sender, so that a series of messages, or a virtual conversation. tends to develop around a number of themes or issues.

Subscribers to OCD-L have access to an archive of all previous messages posted to the list, as well as to a list of frequently asked questions (FAQs) with accompanying answers. In addition, a number of well-known professionals have agreed to participate in the list. answering questions which are posed to them by list members.

A questionnaire was devised to obtain basic demographic data of members of the list, and to elicit possible benefits and problems of membership. The questionnaire was revised after comments and suggestions were obtained from the owner of OCD-L. All members of OCD-L were sent the questionnaire by e-mail via the server, and two reminders were subsequently also posted.

Response rate to the questionnaire was 42 out of $163(25.8 \%)$. Data from returned questionnaires were tabulated and analysed. 


\section{Findings}

Thirty of the 42 respondents (71.4\%) suffered from OCD, $10(23.8 \%)$ had a family member or significant other with OCD, and two $(4.8 \%)$ were mental health professionals who treated OCD. Mean age of subscribers was 39.1 years (s.d.=10.8, range 13-61), while mean age of onset of OCD was 13.7 years (s.d.=7.3). Twenty-eight $(66.7 \%)$ of the respondents were women, while 14 (33.3) were male.

In $38(95.0 \%)$ of the 40 lay members, the diagnosis of OCD had been made by a professional. Seven of the $40(17.5 \%)$ had previously been in treatment, while 32 of the $40(80.0 \%)$ were currently in treatment with a mental health professional.

Most of the subscribers ( $31 / 42$ or $73.8 \%$ ) had come across OCD-L while "surfing" or exploring the Internet. Additional sources of referral included referral by OCD consumer organisations. friends and family members.

The majority of respondents had subscribed to the list for $1-3$ months $(12 / 42,28.6 \%), 3-6$ months $(11 / 4226.2 \%)$, or longer $(10 / 42$, 23.8\%). Many respondents stated that they read or responded to the list once $(17 / 42,40.5 \%)$. twice $(7 / 42,16.7 \%)$, or more than twice $(8 / 42$, $19.0 \%$ ) a day. Most respondents devoted 1-2 hours $(16 / 42,38.1 \%)$ or $2-5$ hours $(17 / 42$, $40.5 \%$ ) each week to the list.

Respondents found the list helpful in learning about the symptoms of OCD, about medication and cognitive-behavioural treatment, and in obtaining support (Table 1). A number of direct quotations from the questionnaires give a flavour of the advantages and problems of OCD-L:

"I have found [this list] much more helpful than any books I've read. . . . I now realize I have had $O C D$ for years, but l've only recently known what to call it. This list has helped TREMENDOUSLY in terms of feeling supported and dealing with the coming out process of seeing myself as a person with OCD. I read about people with some of the same symptoms I have, and I have great compassion for them and for myself. I'm not just weird or bad or lazy - I really do have $O C D$. and it really does have some strong effects in my life. I've been able to take action and confront some of my fears, just knowing that the other people from this list were out there, struggling with some of the same issues. I am incredibly grateful for this list and for those on it".

"Even now, friends really cannot grasp the full depth and breadth of the problem. Yet, I know, sadly. everyone on this list who also has $O C D$ and fears contamination knows almost exactly what I am talking about ... they understand the suffering. the embarrassment, and how exhausting and difficult it is to have OCD. I am truly thankful for this list".

"This is my real information source. Good or bad, it's all I really get. Docs information is sparse and usually preprinted material. This is interactive and deals quickly with the question of the day".

"Information is VERY important to me; I like to know as much as possible about things that are important to me and mine. Hearing from people with OCD makes things my daughter does more understandable to me - these aren't just her quirks, but common to people with OCD. Hearing from other parents makes me less isolated".

"This OCD list has helped [my son] tremendously. He found out that there were other persons with the same problems. He was beginning to think that he was a terrible person deep inside. This list has made him see otherwise, and we are both tremendously thankful for everyone's help. I've had my computer for a while now. but my husband said that if for no other reason, this list is worth the price of purchasing a computer!"

"As a mental health professional, I have perused this list for quite a while and find it very helpful. I feel I learn more from this list about how patients really feel, than what they share with professionals. It has a support group atmosphere, with a very free exchange of information. I often share people's writings from this list with my patients and they say it helps them. Unfortunately, the population I work with in community mental health has little access to computers".

"My 18-year-old daughter has OCD but I can't get her to get involved with this OCD list, despite much gentle encouragement. Similarly, she won't undertake behaviourat-cognittve therapy. Maybe some day".

"Sometimes it seems as though individuals dominate, moralize and wreak symptoms on the group. This is a big turnoff and leaves me unwilling to contribute to the group. I still send prtvate messages back to people who post special notes, though".

Table 1. Rating the helpfulness of OCD-L $(n=42)$

\begin{tabular}{lllll}
\hline & $\begin{array}{l}\text { Definitely } \\
\text { helpful (\%) }\end{array}$ & $\begin{array}{l}\text { Somewhat } \\
\text { helptul (\%) }\end{array}$ & $\begin{array}{l}\text { Somowhat } \\
\text { unhelpful (\%) }\end{array}$ & $\begin{array}{l}\text { Definitiely } \\
\text { unhelpful (\%) }\end{array}$ \\
\hline Learning about symptoms of OCD & 61.9 & 38.1 & 0 & 0 \\
Learning about medication treatment & 48.8 & 48.8 & 2.4 & 0 \\
Learning about cognitive-behavioural treatment & 39.0 & 43.9 & 12.2 & 4.9 \\
Tips about llving with OCD & 57.1 & 40.5 & 2.4 & 0 \\
Helpfulness of the frequently asked questions (FAQs) & 52.0 & 48.0 & 0 & 0 \\
Helpfulness to family or friends & 20.0 & 70.0 & 0 & 10.0 \\
\hline
\end{tabular}


"I personally am annoyed at [. . . ]'s pomposity and know-it-all attitude. I automatically now delete [. . . ]'s posts without reading them".

"Sometimes the group gets off the subject. So far . . . the unofficial moderators are doing a good job of getting it back on track".

Only a few respondents rated the helpfulness of the list to family or friends, as most subscribers with OCD had not shared the list in this way. Similarly, one of the questions also asked whether OCD-L had been useful in terms of encouraging treatment, but 30 of the 40 lay respondents $(75 \%)$ said that the person with OCD had made a decision to obtain treatment prior to joining the list.

Only two respondents stated that they "probably" had been misled by the list. One of these explained that, "Not all opinions are gospel", while the second noted that other members of the list had helped her correct the false information she had read. Corresponding with the list did, however, trigger OCD symptoms (such as hoarding of e-mail messages) in a number of subscribers with OCD (3/30 (10.0\%) definitely; $6 / 30(20.0 \%)$ probably).

\section{Comment}

The main findings of this study of the OCD-L mailing list are that subscribers found the list helpful for learning about the symptoms of a psychiatric disorder and its appropriate treatment, as well as for obtaining support. In their comments about the list, respondents noted the interactiveness of the mailing list, and described it as a virtual community which had provided them with specific information and empathic understanding. Subscribers did not report that the list had misled them in a significant way, and subscribing to the list triggered symptoms in only a minority of respondents. Problems with the list appear to be those that might be experienced in any daily social activity (e.g. not liking another subscriber, developing a symptom that relates to the mailing list).

It is important to note several limitations to these conclusions. First, the sample was perhaps biased to represent subscribers who had found OCD-L helpful - those who have found the list unhelpful are presumably no longer subscribing to the list. Also, the data presented here reflect respondents' views at only one time point, and are likely to change with time. For example, during the time when data was collected, a behaviour therapy expert joined the list and agreed to answer subscribers' questions about this treatment modality. This may result in improved ratings of helpfulness of the list with cognitivebehavioural therapy in the future. Finally, certain problems, such as unresolved feelings about other subscribers, were hinted at by some respondents but were not directly assessed by the questionnaire.

The generalisability of these data are also limited. OCD-L is fortunate in that it appears to have a committed founder and owner, and also in that a number of well-known OCD experts answer subscribers' questions. Other malling lists for OCD and for other psychiatric disorders may not have these advantages. Furthermore, subscribers to OCD-L may be a quite selective sample who already have sufficient material and psychological resources to find access to a computer and to search for and join the mailing list. Similarly, the vast majority of subscribers have sought professional help, typically prior to joining the list. Finally, it is possible that the strength of the medical model in explaining and treating $O C D$ makes Internet $O C D$ forums more reliable sources of information than malling lists devoted to disorders about which less is understood from the neuropsychiatric perspective. However, it may be suggested that for anxiety and mood disorders that share features with OCD (e.g. panic disorder, social phobia), malling lists would also establish virtual communities that are able to provide specific information and empathic support. Furthermore, even for conditions that differ markedly from OCD (e.g. the psychotic disorders), mailing lists for family members might provide benefits similar to those apparent in OCD-L.

The responses that certain subscribers gave pay testimony to the significant therapeutic impact that virtual communities can have on patients and their families. It would seem useful for suitable patients to be referred to OCD-L, and also for interested mental health professionals to join this mailing list. Like other communities, the virtual communities of the Internet are not, of course, problem-free. As the Internet expands, we can expect that it will offer both mental health professionals and consumers increasing resources, and these will require ongoing critical assessment.

\section{Acknowledgement}

Dr Stein is supported by the Lundbeck Fellowship award, the Harry and Dorris Crossley Fund, and by a grant from the Medical Research Council of South Africa. Chris Vertullo, the owner of OCD-L, made useful comments and suggestions on a draft of the questionnaire. The author thanks all members of OCD-L for their participation in the study.

\section{References}

BAER, L., CuKor P., Jenike, M. A., et al (1995) Pilot studies of telemedicine for patients with obsessive-compulstve disorder. American Journal of Psychiatry. 162. 1383-1385. 
Huang. M. P. \& Alessi, N. E. (1995) Psychlatry navigates the web. Psychiatric Times, 8, 32-33.

NOAM. E. M. (1995) Electronics and the dim future of the untversity. Science, 270, 247-249.

Preston, J., BROWN, F. W. \& HARTLEY (1992) Using telemedicine to improve health care in distant areas. Hospital Community Psychiatry, 42, 25-32.
TURKLE. S. (1995). Lfe on the Screen: Identity in the Age of the Internet. New York: Simon \& Schuster.

Dan J. Stein, Director of Research, Department of Psychiatry, University of Stellenbosch, P.O. Bax 19063, Tygerberg 7505, South Africa

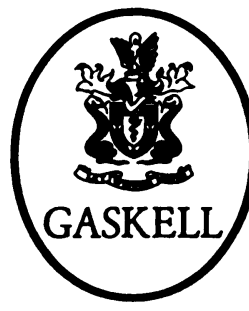

\section{Seminars in Practical Forensic Psychiatry}

\section{Edited by Derek Chiswick \& Rosemary Cope}

Seminars in Practical Forensic Psychiatry is a concise account of the specialty from a strongly practical perspective. It systematically describe the relationship between psychiatric disorders and offending, with detailed discussion of the criminal justice system, court proceedings, mental health legislation, dangerousness, prison psychiatry, and civil issues. There are boxes summarising key points, illustrative case examples, and sample court reports. It is up-to-date, with references to the Reed Report, the Clunis Inquiry, supervision registers and recent legislation. Career guidance and a chapter on ethical issues are included. This book will be invaluable for general psychiatrists and for trainees in forensic psychiatry, as well as those other health and social work professionals having contact with mentally disordered offenders, and those who are part of the criminal justice system. Price $E 17.50,359 \mathrm{pp}$., 1995, ISBN 0902241788

Available from good bookshops and from the Publications Department, Royal College of Psychiatrists, 17 Belgrave Square, London SWIX 8PG (Tel. $0171-235$ 235I, extension 146) 